\title{
O sintagma "progressão continuada" sob a lupa da análise do discurso: um caso de fórmula discursiva?
}

\author{
The Syntagma of "Continuous Progression" \\ under the Magnifying Glass of Discourse \\ Analysis: an Event of Discursive Formula?
}

Rosana de Barros Silva e Teixeira*

Pontifícia Universidade Católica de São Paulo

São Paulo - São Paulo / Brasil

RESUMO: Este artigo apresenta os resultados de uma pesquisa acerca do conceito de fórmula discursiva. Em pauta, está o sintagma "progressão continuada", regime de ciclos implantado em 1998 no estado de São Paulo. Para embasar a análise, os pressupostos teóricos da Análise de Discurso francesa foram eleitos, segundo os quais quatro propriedades incidem na caracterização da fórmula (KRIEG-PLANQUE, 2010): cristalização do significante; caráter discursivo; funcionamento como referente social e aspecto(s) polêmico(s). Em adição, o aporte teórico-metodológico da Linguística de Corpus (BERBER SARDINHA, 2004) foi utilizado a fim de proceder à investigação do corpus (de 432.146 palavras). Os dados, provenientes de gêneros discursivos variados, referem-se ao período de 1997 a 2011. Por meio deles, foi possível concluir que "progressão continuada" pode ser considerada uma fórmula, uma vez que os traços que a definem sinalizam sua constituição discursiva.

PALAVRAS-CHAVE: fórmula discursiva, análise do discurso francesa, linguística de corpus.

ABSTRACT: This paper presents the results of research carried out on the concept of the "discursive formula", as defined by Krieg-Planque (2010). At issue is the phrase "continuous progression" - learning cycles implemented in 1998 in the state of São Paulo. The theoretical assumptions of French Discourse Analysis were selected to support this analysis, based on the four properties which affect the characterization of the discursive formula (KRIEG-PLANQUE, 2010): the crystallization of the signifier, discursive character, functioning as social reference, and controversial aspect(s). In addition, the contribution of the theoretical and methodological framework of Corpus Linguistics (BERBER SARDINHA, 2004) was used to investigate the corpus, which contains 432,146 words. The data,

*rosana.tex@ig.com.br 
from various discursive genres, refer to the period between 1997 and 2011. Through these, it could be concluded that "continuous progression" can be considered a formula, since the traits that define it signal its discursive constitution. KEYWORDS: discursive formula, French discourse analysis, corpus linguistics.

\section{Introdução}

Mais de uma década após a sua implantação, o regime de progressão continuada em sistema de ciclos, normatizado no Estado de São Paulo pelo Conselho Estadual de Educação (CEE) ${ }^{1}$ por meio da deliberação de n. ${ }^{\circ}$ 8/ 1997, parece continuar gerando polêmica ${ }^{2}$ entre educadores, pais, alunos e gestores da administração pública.

Trata-se de uma política educacional instituída em 1998, durante o mandato do então governador Mário Covas, segundo a qual o aluno do Ensino Fundamental não é mais reprovado ao fim do ano letivo, mas somente ao término de um ciclo, ou seja, no $5 .^{\circ}$ ano (antiga $4 .^{\mathrm{a}}$ série) e/ou no $9 .^{\circ}$ ano (antiga $8 .^{\text {a }}$ série). ${ }^{3}$

${ }^{1}$ Atua como órgão normativo, deliberativo e consultivo do sistema educacional
público e privado paulista. É quem estabelece regras para todas as escolas de todas as redes - estaduais, municipais e particulares - de educação infantil, ensino fundamental, ensino médio e profissional, seja presencial ou a distancia. Também cabe ao CEE-SP orientar as instituiçōes de ensino superior públicas do Estado, bem como credenciar seus cursos. Esta atribuição lhe é dada tanto pela Constituição Estadual quanto pela lei que o criou em 1963. Trata-se de órgão de esclarecimento e de proposta de soluções. Seus interlocutores são o governo e a comunidade e seu objetivo é qualificar a educação paulista, pública e privada, de todos os níveis. Para mais informaçôes, vide <(http://www.ceesp.sp.gov.br/portal.php/conheca_cee>.

${ }^{2}$ As Horas de Trabalho Pedagógico Coletivo (HTPCs) contribuíram para fundamentar minha suposição. Como professora efetiva da rede pública estadual de São Paulo desde 2004, tenho participado dessas reuniōes, em que, frequentemente, professores, coordenadores, diretores e vice-diretores discutem o regime de progressão continuada, seus benefícios e entraves para a rede pública de ensino. Além disso, o contato com alguns pais durante as reuniōes bimestrais tem favorecido minha hipótese.

${ }^{3}$ A proposta da Secretaria Estadual da Educação para 2014 é a de que a retenção possa ocorrer no $3 .^{\circ}, 6 .^{\circ}$ e $9 .^{\circ}$ anos. Assim, o número de ciclos subiria de dois para três. Mais detalhes estão disponíveis em <http://www.educacao.sp.gov.br/noticias/ aprimoramento-da-progressao-continuada-reestrutura-ciclos-do-ensinofundamental>. Acesso em novembro de 2013. 
Em princípio, o processo deve funcionar assim: mesmo que o aluno não apresente rendimento suficiente, ele deve ser promovido à série seguinte, com exceção das séries que encerram ciclos (vide explicação acima), respaldado por um conjunto de medidas pedagógicas, tais como estudos suplementares durante as férias de verão e recuperação contínua e paralela pelo tempo que se fizer necessário, de modo que a apropriação dos conhecimentos sistematizados ao longo de cada ciclo seja garantida (OLIVEIRA, 1998).

Sustentada pelo que dispõem os artigos 23 e 32 da Lei de Diretrizes e Bases da Educação Nacional (LDBN 9.394, de 20 de dezembro de 1996), essa modalidade pedagógica propóe, para o êxito de sua execução, que o educando seja avaliado de forma constante, contínua e cumulativa (Art. 24, V-a), o que significa dizer que a avaliação deve ter função orientadora e cooperativa, ao contrário das propostas de cunho classificatório até então executadas (HAMZE, s/d).

Com o foco deslocado de resultados pontuais para o processo como um todo, reprovações sucessivas parecem perder fundamento por não contribuírem para a melhoria do aprendizado (FONTES, 2001; PEREIRA ETERRAZZAN, 2005). Nas palavras de Pereira (2006, p. 5):

A repetência traz sérios prejuízos à aprendizagem do educando. E também tem um alto custo para os governos [...]. Isso porque, devido à reprovação, o aluno vai rever os mesmos conteúdos, com os mesmos métodos e com colegas mais novos e, muitas vezes, sendo rotulado de repetente, fracassado, 'burro', entre outros, resultando, possivelmente, na indisciplina, agressividade e na baixa estima.

Atrelados ao aspecto comportamental, outros fatores ensejam a adoção de um sistema de ensino não seriado. Entre eles, destacam-se a defasagem idade/série, a evasão escolar ${ }^{4}$ e a qualidade de ensino. De acordo com Jesus (2011) e Petrenas; Lima (2006), a progressão continuada permite que o processo individual de amadurecimento cognitivo de cada ser humano seja respeitado, o que vem favorecer a inclusão social e, consequentemente, o exercício da cidadania, como previsto no artigo 205 na Constituição Federal.

\footnotetext{
${ }^{4}$ Em São Paulo, desde que foi implantada, em 1998, a progressão continuada para alunos de $1 .{ }^{\mathrm{a}}$ a $4 .^{\mathrm{a}}$ série foi possivelmente o que fez com que a evasão escolar apresentasse uma grande queda. No ensino fundamental, passou de 4,5\% em 1999 para 1,3\% em 2009 (VIEIRA, 2010).
} 
No Brasil, a ruptura com a organização seriada de ensino teve início nos anos 1980, a partir da implantação de ciclos nas séries iniciais da educação básica (Ensino Fundamental) (GUILHERME, 2000).

Apesar de ser considerada uma proposta avançada por especialistas em Educação - CORTELLA (2002) e CHALITA (2002), para ficar em apenas dois exemplos -, a progressão continuada ainda hoje é alvo de controvérsias. Para muitos, ela configura a aprovação automática dos alunos, uma vez que as condições estruturais, pedagógicas, salariais, de formação dos professores, entre outras, indispensáveis ao desenvolvimento de uma proposta pedagógica alicerçada em um sistema de ciclos, não foram levadas a cabo.

\section{Sobre a proposta desta pesquisa}

Retomando as condições de emergência e de implantação do regime de progressão continuada, é possível entrever uma polarização da opinião pública. Esses primeiros indícios acabaram por motivar a investigação desse sintagma sob a perspectiva da Análise do Discurso, a fim de categorizá-lo (ou não) como fórmula discursiva. Isto é, enquadrá-la num "conjunto de formulações que, pelo fato de circularem em um momento e um espaço público dados, cristalizam questōes políticas e sociais que essas formulaçóes contribuem, ao mesmo tempo, para construir" (KRIEG-PLANQUE, 2010, p. 9).

Para tanto, quatro propriedades de cunho linguístico-discursivo devem compor o objeto, segundo a autora: cristalização do significante; dimensão polêmica; inscrição discursiva e funcionamento como referente social. Entretanto, cabe ressaltar que, para Krieg-Planque, se por um lado os traços que caracterizam uma fórmula possuem contornos precisos, por outro, essa categoria é de natureza fluida, ou seja, gradual: "as propriedades [...] só são de fato verificáveis em continua, e não mensuráveis em termos de presença ou ausência” (KRIEG-PLANQUE, 2010, p. 111).

No que tange às discussóes concernentes aos entraves ou às contribuiçóes para o trabalho docente, bem como a repercussão positiva ou negativa desse sistema no processo ensino/aprendizagem, tais questóes serão aqui apenas tangenciadas em conformidade com o aporte teórico da Ergologia (SCHWARTZ, 2000 e TRINQUET, 2010). Tal abordagem, que surgiu na França (Universidade de Provence), no início da década de 1980, pretende conhecer e intervir sobre as situações reais de trabalho, com o objetivo de transformá-las, a partir de uma perspectiva humanizadora. Isto é, o sujeito-trabalhador passa a protagonista da atividade. 
Para dar suporte à pesquisa, um corpus sincrônico, composto de gêneros diversificados das modalidades escrita e oral, foi coletado de acordo com os pressupostos da Linguística de Corpus ${ }^{5}$ (BERBER SARDINHA, 2004). O objetivo foi recobrir, nos limites de um período histórico determinado, as possibilidades de uso do sintagma, no intuito de apreender o feixe de acepções que parecia acompanhá-lo.

Na próxima seção, detalharei a constituição e a procedência desses dados.

\section{O corpus de estudo}

Os dados da pesquisa, provenientes de artigos acadêmicos e de opinião, fóruns, notícias, reportagens, entrevistas, teses de doutorado, leis, resumo e pronunciamentos, compreendem o intervalo de 1997 e 2011. Como outrora mencionado, tamanha diversidade de gêneros pretendeu rastrear os diferentes lugares discursivos ${ }^{6}$ pelos quais a sequência linguística circulou, enquanto o recorte temporal procurou recobrir a repercussão do regime desde sua gênese até o início da década atual.

Quanto à dimensão do corpus, ele pode ser classificado como médio e, do ponto de vista de sua origem, de amostragem, já que representa uma amostra finita da linguagem (BERBER SARDINHA, 2004).

A seguir, na tabela 1 , exponho a composição do corpus e a distribuição do número de palavras por gênero, conforme o programa WordSmith Tools 3.0 (SCOTT, 1999).

\footnotetext{
${ }^{5}$ A Linguística de Corpus ocupa-se "da coleta e da exploração de corpora, ou conjunto de dados linguísticos textuais coletados criteriosamente, com o propósito de servirem para a pesquisa de uma língua ou variedade linguística. Como tal, dedica-se à exploração da linguagem por meio de evidências empíricas, extraídas por computador" (BERBER SARDINHA, 2004, p. 3). Graças à digitalização dos dados - o equivalente a aproximadamente 1.094 páginas de 395 palavras cada, segundo o Word 2007 -, foi possível fazer uso da suíte WordSmith Tools 3.0 (SCOTT, 1999), em especial do concordanciar (Concord), um programa que produz, automaticamente, linhas de concordância de um item lexical, chamado de palavra de busca ou nódulo. Essas linhas correspondem às ocorrências do nódulo, que vem centralizado e acompanhado do cotexto - e do contexto que o circunda, caso se deseje -, permitindo uma visão privilegiada do item.

${ }^{6}$ Para Krieg-Planque, eles podem ser, no plano formal, textos, unidades lexicais, associações léxico-sintáticas, datas ou números. No plano das funções do discurso, textos-chave, provas autentificadoras, índices de historicidade, slogans, palavras de ordem, designantes ou ainda fórmulas (MOTTA; SALGADO, 2011).
} 


\section{TABELA 1}

Composição do corpus de estudo, com o respectivo número de palavras por gênero

\begin{tabular}{lc}
\hline Gêneros Discursivos & Tokens(Palavras) \\
\hline artigo acadêmico & 59.013 \\
entrevista & 6.722 \\
fórum de discussão & 79.826 \\
lei (deliberação e LDB) & 4.549 \\
livro & 2.940 \\
artigo de opinião & 34.224 \\
notícia & 9.899 \\
pronunciamento em conferências & 17.969 \\
pôster & 1.664 \\
reportagem & 10.724 \\
tese & 204.407 \\
resumo de artigo acadêmico & 209 \\
\hline TOTAL & 432.146 \\
\hline
\end{tabular}

A partir das informações por ora apresentadas, discorrerei, na próxima seção, a respeito do caráter estável da fórmula, considerando a perspectiva do significante.

\section{A cristalização do significante}

Ao afirmar que fórmulas possuem caráter cristalizador, Krieg-Planque aponta para a materialidade linguística do objeto, destacando a relativa estabilidade da forma (significante), que a torna facilmente reconhecível.

Do ponto de vista estritamente linguístico, uma fórmula pode se manifestar em uma unidade lexical simples (uma palavra), em um sintagma (expressão) ou mesmo em uma sequência autônoma (frase). No caso de "progressão continuada", tem-se um sintagma do tipo nominal em que ocorre uma nominalização (progressão) em associação com um adjetivo deverbal (continuada).

Como a noção de cristalização está diretamente associada à de uso (enunciados atestados), um olhar atento ao corpus de estudo (vide descrição no item 3) mostrou que esse sintagma ocorreu 1.045 vezes. No Corpus 
Brasileiro, ${ }^{7}$ que contém, em média, 1 bilhão de palavras, 625 repetições da sequência linguística foram apuradas, o que parece indicar o caráter relativamente estável de "progressão continuada".

$\mathrm{Na}$ esteira dos critérios sintáticos, medidas estatísticas de associação, preconizadas pela Linguística de Corpus, podem contribuir para corroborar o quão estável é a relação entre itens lexicais de um candidato a fórmula, a despeito de uma combinação espúria. Nos quadros a seguir, os valores obtidos para "progressão continuada", considerando o tamanho do corpus, a frequência do nódulo (palavra de busca) e do colocado, ${ }^{8}$ parecem garantir a lexicalização do sintagma na língua portuguesa, posto que cada medida aborda a questão da não aleatoriedade entre nódulo e colocado de perspectivas diferentes. Desse modo, a coocorrência pôde ser comprovada.

\section{QUADRO 1}

Medidas estatísticas de associação conforme valores do corpus de estudo

Escore T: 32,20 (mín. aceitável = 2)

Informação Mútua: 8,11 (mín. aceitável = 3)

Razão Observado/Esperado: 276,85

Baseados nos dados abaixo:

Freq. do nódulo progressão f(n): 1.307

Freq. do colocado continuada f(c): 1.248

Freq. do nódulo e do colocado juntos: 1.045

Tamanho do corpus: 432.146

\footnotetext{
${ }^{7} \mathrm{O}$ Corpus Brasileiro é o maior acervo autêntico da língua portuguesa brasileira contemporânea. Foi compilado pelo Grupo de Estudos de Linguística de Corpus e está sediado no Centro de Pesquisas, Recursos e Informação de Linguagem (CEPRIL), do Programa de Pós-Graduação em Linguística Aplicada e Estudos da Linguagem (LAEL), da PUC-SP. Para mais informações, consulte: <http:// corpusbrasileiro.pucsp.br/cb/Inicial.html>.

${ }^{8}$ Palavra(s) que ocorre(m) com outra(s) (SINCLAIR, 1991). Trata-se de uma característica linguística cuja comprovação é feita mediante medidas estatísticas de associação.
} 


\title{
QUADRO 2
}

Medidas estatísticas de associação conforme valores do Corpus Brasileiro

\author{
Escore T: 24,99 (mín. aceitável = 2) \\ Informação Mútua: 12,01 (mín. aceitável = 3) \\ Razão Observado/Esperado: 4,128 \\ Baseados nos dados abaixo: \\ Freq. do nódulo progressão f(n): 11.696 \\ Freq. do colocado continuada f(c): 14.087 \\ Freq. do nódulo e do colocado juntos: 625 \\ Tamanho do corpus: 1.088 .218 .912
}

Como é possível depreender das informações exibidas nos quadros, existem três medidas: razão observado/esperado, informação mútua (MI) e o escore T (T-Score). Para calculá-las, utilizei a calculadora virtual ${ }^{9}$ disponível no site <http://lael.pucsp.br/corpora/association/calc.htm>.

A razão observado/esperado permite saber se o valor observado (quantas vezes as palavras ocorreram juntas) corresponde a quantas vezes seria esperado que elas coocorressem (valor esperado). Nesta pesquisa, considerou-se que o colocado (vide nota 8) era imediatamente consecutivo ao nódulo (horizonte 0:1).

A segunda medida de associação, informação mútua (MI), não prevê, como a anterior, a direcionalidade do colocado, isto é, este pode estar tanto nas proximidades do nódulo quanto imediatamente antes ou posterior a ele. Para que o resultado seja considerado satisfatório, é necessário que seja maior que 3, quando da aplicação da seguinte fórmula (BERBER SARDINHA, 2004, p. 204): I = $\log _{2} \mathrm{O} / \mathrm{E}$, em que I significa informação; $\log _{2}$, logaritmo na base 2; O, Observado; E, Esperado.

Ao levar em conta a posição do nódulo e do colocado (0:1), o escore $T$ sugere que resultados maiores que 2 constituem associações não aleatórias entre palavras. A fórmula para o cálculo dos valores é (BERBER SARDINHA, 2004, p. 205): $\mathrm{T}=(\mathrm{O}-\mathrm{E}) /($ raiz quadrada de $\mathrm{f}(\mathrm{n}, \mathrm{c}) / \mathrm{N})$, em que $\mathrm{T}$ é igual a T-score; O, a Observado; E, a Esperado; $\mathrm{f}$ (n,c), a frequência da ocorrência mútua do nódulo e do colocado; $\mathrm{N}$, a tamanho do corpus.

Em suma, tomando por base os valores de "progressão continuada" tanto no corpus de estudo quanto no Corpus Brasileiro, a associação entre os itens

\footnotetext{
${ }^{9}$ Nos quadros aqui apresentados, foi feita tradução. Na calculadora online, todos os campos encontram-se em língua inglesa.
} 
lexicais do sintagma foi, em ambos os casos, legitimada pela frequência (TScore) e pela preferência (Mutual Information) com que coocorreram.

Se, por outro lado, apelarmos para critérios semânticos, como a não composicionalidade do sentido, também conhecida por imprevisibilidade semântica (o sentido da expressão não é depreendido pelo significado de cada uma das partes que a compõem, mas pelo todo que representa), a estabilidade parece se manter: o sentido de "progressão" acrescido do de "continuada" não corresponde ao sentido que o bloco "progressão continuada" representa, qual seja, regime de ciclos.

Embora Picoche ([1977] 1992) frise que "tais critérios constituem antes indicaçōes que provas", eles parecem reforçar, em termos de língua, a cristalização do sintagma, ao lado de outra condiçãa: certa concisão, ponto defendido não só pela autora, mas também por linguistas como Kocourek (1991), para o qual sintagmas lexicalizados normalmente são menores que sintagmas livres.

Pesquisadora das linguagens especializadas, Barros (2004) também defende que um sintagma muito grande normalmente não é funcional, o que parece explicar, no âmbito do sistema linguístico, a brevidade observada por Krieg-Planque.

No que diz respeito a "progressão continuada", a concisão é validada pelo apagamento dos dois primeiros itens lexicais da sequência "regime de progressão continuada" que, ao somar 131 ocorrências no corpus de estudo, demonstra ser, aproximadamente, 8 vezes menos empregada que sua versão reduzida.

$\mathrm{Na}$ esfera do significante há, ainda, outra situação a se considerar, conforme Krieg-Planque: as variantes de uma fórmula. Ao circularem no espaço social, elas podem contribuir para acentuar sobremaneira as tensóes que acarretam as polêmicas. Sobre essa questão tratarei a seguir.

\section{As variantes e a dimensão polêmica}

Se a estabilidade do significante constitui um dos pilares sobre os quais está assentada a noção de fórmula discursiva, pode ser a partir de suas variantes (ou paráfrases ${ }^{10}$ ) que a polemicidade venha à tona:

${ }^{10}$ Entendidas aqui como parassinônimos. 
Insistamos no fato de que as formulaçōes concorrentes não são 'sinônimos em língua' da fórmula, de que uma análise sêmica, por exemplo, daria conta, ou algo que os dicionários de língua pudessem indicar; mas são sequências que funcionam de modo efetivo no discurso, como substitutos mais ou menos polêmicos, e mais ou menos mutualmente exclusivos (KRIEG-PLANQUE, 2010, p. 70-1, destaque meu).

Seja no interior de uma série lexical (modificações morfológicas/ morfossintáticas), seja como substituto em contexto (sinônimo sociopragmático), essas formulaçóes concorrentes podem dizer muito sobre os posicionamentos discursivos que orbitam em torno delas.

Um exemplo é a expressão "exclusão postergada" (2 ocorrências), usada pela presidente da Apeoesp (Sindicato dos Professores do Ensino Oficial do Estado de São Paulo) para fazer referência a "progressão continuada" no título e no corpo de um artigo de opinião: "Da forma como foi implementada, a progressão continuada em São Paulo concretizou, na verdade, a éxclusão postergada' dos alunos, que terão menos chance na vida e no mundo do trabalho" (NORONHA, 2011).

Do mesmo modo, ao subverter "progressão continuada" a "regressão continuada" (2 ocorrências), o então candidato do Partido dos Trabalhadores (PT) ao governo de São Paulo nas eleições de 2010, Aloizio Mercadante, acabou por contribuir para que a polêmica se instaurasse: "O que nós temos hoje em São Paulo não é uma progressão continuada, é uma regressão continuada para grande parte dos alunos. Estamos vivendo uma situação em que os alunos nem sequer aprendem a ler e a escrever" (R7, 2010).

Alternativas ainda mais conflituosas, "promoção automática" e "aprovação automática”, levam a crer, pela frequência de uso (131 e 153 ocorrências, respectivamente) e pelo teor das declarações, que o sintagma "progressão continuada" catalisa uma pletora de críticas:

(1) "O que a opinião pública desconhece é que, independente da duração dos ciclos, existe nas Secretarias de Educação uma política descarada de promoção automática” (MELO, 2011).

(2) "Colocar as crianças no centro da ação pedagógica não significa apenas amálas e se preocupar com seu futuro; não é uma questão de sentimento, mas de didática, de competências e de habilidades. Não foi possível, ainda, evitar que a progressão continuada se confundisse com a promoção automática" (LEME, 2002). 
(3) "A progressão continuada se tornou aprovação automática e o aluno com dificuldades não consegue acompanhar o conteúdo em sala de aula, fica desmotivado e opta pela indisciplina" (O EDUCACIONISTA, 2011).

(4) "A associação da progressão continuada com a aprovação automática configura o desvirtuamento desse modelo importante [...]" (CHRISTIANO, 2010).

Por vezes, a incompatibilidade entre referente, designação e predicação é tão pregnante que a tentativa de delimitar as fronteiras entre os conceitos é não só recorrente, mas também explícita:

(5) "É vergonhosa a defesa do Ministério da Educação da progressão continuada, ou melhor, da "promoção automática" (FUNDAÇÃO BUNGE, 2011).

(6) "A expressão promoção automática, todavia, parece menos adequada do que progressão continuada, aquela se referindo principalmente à ação administrativa e esta, ao aluno e ao seu desenvolvimento" (BERTAGNA, 2003).

(7) "É importante explicitar a diferença entre progressão continuada e aprovação automática [...]" (BERTAGNA, 2008).

(8) "A ideia da 'progressão continuada' na educação básica, formulada por Paulo Freire, não é a chamada 'promoção automática' dos dias de hoje" (FELICÍSSIMO, 2011).

(9) "A confusão entre os conceitos prejudica os debates sobre os ciclos de aprendizagem [...] Aprovação automática quer dizer sem avaliação, sem orientação, sem cobrança, sem algum apoio. [...] Progressão continuada, ao contrário, é um alargamento do conceito de período escolar, pois prevê, em vez de anos, ciclos" (ALMEIDA, 2010).

Cumpre observar que essa tensão conceitual entre os pares "progressão continuada" e "aprovação automática” abriu espaço também para a materialização, na língua, de outros sinais, a partir dos quais é possível inferir uma situação de polêmica.

Em (5), por exemplo, ocorre um fenômeno enunciativo descrito por Jacqueline Authier-Revuz (1995): a modalização autonímica, em que não há coincidência entre as palavras e as coisas. Ela manifesta-se na matriz "x, ou melhor, y" e demonstra a incongruência entre nome e referente. Por conseguinte, o enunciador, ao corrigir a própria fala, fornece indícios de que tomar um objeto pelo outro pode desembocar em embate. 
O exemplo (8), por sua vez, ilustra o que a autora cunhou de heterogeneidade mostrada, mas não marcada (AUTHIER-REVUZ, [1982] 2004). Ela emerge do item lexical chamada ("não é a chamada 'promoção automática’ dos dias de hoje”). Para Gallo (2001), “[...] entregando-se à evidência de uma voz que fala nele, o sujeito delimita o campo de ação dessa voz [...]". Assim, o emprego de chamada, no fragmento, parece pôr em cena o "outro" com o qual o enunciador rivaliza, sem explicitá-lo (são os opositores da progressão continuada que a chamam de promoção automática e não eu!). Eis a brecha para a polêmica, que reside justamente nessa falta de aderência do enunciador ao que está pressuposto.

Para além das possíveis marcas de alteridade que têm acompanhado as variantes discursivas arroladas até aqui, constam ainda, no caso em análise, as concorrentes "avanço progressivo" (2 ocorrências), "aprovação contínua/ continuada (1 ocorrência)" e "exclusão automática" (2 ocorrências). Em todas as situaçôes, a celeuma permanece:

(10) "Em qualquer sistema educacional sério e desde sempre a progressão continuada, ou avanço progressivo [...] é um princípio fundamental" (PORTAL LUÍS NASSIF, 2008).

(11) "Há muita confusão, pois esse conceito [de progressão continuada] é imediatamente confundido com 'aprovação continua' ou 'aprovação automática." (ALMEIDA, 2010)

(12) "Sou aposentado como diretor de escola e estive na rede quando foi imposta esta tal 'progressão ou aprovação continuada', pelos 'excelentes' pedagogos do PSDB” (PORTAL LUÍS NASSIF, 2008).

(13) "Sem bons mestres, educação com progressão continuada ou seriada vira exclusão automática no mercado de trabalho" (CHACON, 2010).

Tais trechos parecem demonstrar o quão acirrado é o debate em torno da conceitualização de "progressão continuada", considerando-se o que ela (leiase bem) efetivamente representa como sistema educacional. Aqui, a dicotomia teoria/prática talvez possa jogar luzes sobre a discussão: a proposta teórica batizada de "progressão continuada" não está, segundo o que foi afirmado, condizente com o que se tem praticado como regime de ciclos, o que parece explicar o emprego de designaçóes divergentes para, em tese, um mesmo referente. A declaração, abaixo, sustenta tal suposição: 
[...] 'na forma em que foi adotado, o programa ou modelo passa a exigir do aluno, apenas e tão somente, que tenha frequência escolar mínima, sem comprometimento com a absorção de conteúdos', o que tem sido 'extremamente danoso à Infância e Juventude' [...] Diversos estudos têm apontado que a ideia original da progressão continuada, aplicada com sucesso em outros países - como forma de evitar a estigmatização do aluno reprovado e consequente evasão - acabou distorcida, transformando-se em mera promoção automática, 'desestimulante do estudo e em verdadeira maquiagem às carências do sistema educacional' (ZBD ${ }^{11}$ in CONTEE, 2009).

Tem-se estabelecido, assim, uma clivagem: de um lado, os que concebem o regime como deteriorização do processo educativo (14); de outro, os que o compreendem como solução (para a reprovação e a evasão escolar, principalmente) (15). Como numa arena, posicionamentos discursivos ${ }^{12}$ antagônicos se digladiam em defesa da própria identidade discursiva. Comparemos:

(14) "Sou contra. Se por um lado a progressão continuada possivelmente diminuiria a evasão escolar, por outro lado, está criando uma geração de alunos que se acostumou a ser sempre ajudada, sempre "empurrada" [...] Sou contra, a educação está se deteriorando e temos cada vez mais analfabetos adultos e funcionais, acredito que o maior benefício que o sistema possa trazer esteja direcionado a tentar burlar números de ONU, UNESCO, com a simples pretensão de subir degraus num ranking mundial de formação e diminuição do índice de analfabetismo no país, por simples pretensão de disputas de partidos políticos [...]" (FUNDAÇÃO BUNGE, 2011). / "Eu sou contra esse governo de ninguém repetir, eu acho muito errado porque isso vai ser difícil para eles no futuro quando forem procurar emprego, serviço e eles não vão saber nada [...] (BERTAGNA, 2003).

(15) "Eu sou a favor da progressão continuada porque antigamente os alunos ficavam, por exemplo, reprovados dois, três anos, na $1 .^{a}$ série [...]" (BERTAGNA, 2003) / "Eu sou a favor da progressão continuada. Ela pode não ser perfeita, mas tem vários benefícios: muitos alunos repetentes, pela humilhação, acabam desistindo da escola [...]”. (MLRODRIG, 2010).

\footnotetext{
${ }^{11}$ Com o objetivo de preservar a identidade de quem depôs, mantive somente as iniciais dos nomes, que são fictícias.

${ }^{12}$ Orlandi (2007, p. 20) define posicionamentos discursivos (a autora chama de formaçōes discursivas) como "distintas regiōes do dizível para os sujeitos". Para ela, [as formações discursivas] [...] "refletem as diferenças ideológicas, o modo como as posiçôes dos sujeitos, seus lugares sociais aí representados constituem sentidos diferentes".
} 
Em face dos depoimentos acima, é possível concluir que o sintagma "progressão continuada", ao mobilizar os indivíduos para que se manifestem, de fato apresenta uma dimensão polêmica, que põe à prova os usos discursivos do termo em questão; daí ser a fórmula uma noção também, e essencialmente, discursiva (KRIEG-PLANQUE, 2010). É justamente esse ponto de vista que examinarei na próxima seção.

\section{A inscrição discursiva}

Ora, se atores sociais acenam de determinada posição é porque se inscrevem discursivamente no terreno de uma dada formação discursiva (vide nota 12); logo, cada qual investe "progressão continuada" de um sentido particular. Para explicar esse fenômeno, recorro a Pêcheux, que afirma:

[...] todo enunciado é intrinsecamente suscetível de tornar-se outro, diferente de si mesmo, de se deslocar discursivamente de seu sentido para derivar para um outro (a não ser que a proibição da interpretação própria ao logicamente estável se exerça sobre ele explicitamente). Todo enunciado, toda sequência de enunciados é, pois, linguisticamente descritível como uma série (léxico-sintaticamente determinada) de pontos de deriva possíveis, oferecendo lugar a interpretação. (PÊCHEUX , 2008, p. 53).

Lugar esse que só pode ser legitimado pelo uso que se faz da fórmula em determinado contexto sócio-histórico. Por exemplo, à parte o contexto educacional, "progressão continuada" parece só ser aplicada, segundo o motor de busca do Google, no campo da medicina (1 ocorrência: "progressão continuada [da doença]"), ${ }^{13}$ da educação física (1 ocorrência: "Progressão continuada [da prática de pilates]") $)^{14}$ e da segurança pública (1 ocorrência: "progressão continuada de pena a criminosos") $)^{15}$ do que se conclui que, embora outros sentidos da sequência possam circular formalmente, a predominância é do uso como regime de ciclos. Ou seja, é dentro do campo da educação que os sentidos

13 Disponível em: <http://www.renandomingues.med.br/info-doencas-neuro/ doencas-desmielinizantes-aula-basica.pdf>. Acesso em janeiro de 2013.

${ }^{14}$ Disponível em: <http://www.pilatesstudium.com/Index/id=03Cat2.php $>$. Acesso em janeiro de 2013.

15 Disponível em: <http://www.estadao.com.br/arquivo/cidades/2007/ not20070109p14846.htm>. Acesso em janeiro de 2013. 
antagônicos do sintagma emergem, evidenciando formaçōes discursivas de feição igualmente opostas. Tomo como ilustração os seguintes excertos:

(1) "A progressão continuada não é boa só por diminuir a evasão escolar, ela a diminui, também. Mas, o conceito da progressão continuada é o fato de que todo mundo pode aprender. E que o processo de aprendizagem não precisa ser o mesmo para todos os alunos. $\mathrm{O}$ discurso educação-inclusão, que é fundamental, faz com que uma escola nãofique segregando, discriminando determinado tipo de aluno, mas sim que incorpore a noção de que ele possa aprender na sua própria capacidade cognitiva para aprender. Talvez esse aluno tenha determinadas limitações, não tenha como desenvolver algum tipo de habilidade, mas desenvolve outras. E o professor consegue acompanhar esse processo [...]” (CHALITA, 2002).

(2) "Quando se fala de aprendizagem, fixa-se na ideia de conteúdo. Não estou desprezando que o aluno deva aprender conteúdos. Eu quero que ele aprenda a ler e a escrever bem, para o resto da vida. Mas ele está aprendendo a coexistir. Ele está se socializando. Portanto, se é importante a permanência dele na escola, se a escola vale alguma coisa, a progressão continuada tem muito a contribuir. Eu acho que se poderia também examinar por aí." (GATTI, 2002).

(3) "A aprovação ano após ano, sem avaliação do conteúdo dominado pelo aluno, permite que muitos estudantes terminem o ensino médio sem terem o conhecimento mínimo necessário, alerta CL, ${ }^{16}$ professor de física e matemática das redes municipal e estadual de São Paulo. 'É a aprovação a qualquer custo', identifica." (VIER, 2010)

(4) “'O que temos é uma forma falsa de incluir a todos na escola, dando a impressão de que estão incluídos, mas de fato a exclusão continua mesmo com o aluno dentro da escola. Se chegar aos 14 anos matriculado na escola e sem saber ler ou escrever não for exclusão, não sei o que seria', arremata NMKW, professor da rede pública estadual em Diadema, SP'.” (OBSERVATÓRIO DA EDUCAÇÃO, 2006)

É visível, a partir das exposições feitas, a natureza discursiva de "progressão continuada": para os representantes da formação discursiva a favor do regime, ela é desenvolvimento de habilidades, forma de socialização; para os que integram a formação discursiva que se opõe ao sistema, ela é exclusão, aprovação a qualquer custo.

${ }^{16}$ Optei por omitir o nome dos depoentes a fim de preservar a identidade deles. As iniciais são, portanto, fictícias. O mesmo foi feito em (4). 
Esse modo de interação semântica entre os discursos, Maingueneau chama de interincompreensão regrada. Ela é resultado do processo de "tradução" dos enunciados do Outro, ${ }^{17}$ cuja compreensão toma a forma de simulacro (MAINGUENEAU, 2008). O simulacro pode ser entendido como uma espécie de "véu" que impede um discurso de ver o discurso-outro nitidamente, como ele mesmo se concebe.

Nesta análise, algumas das variantes (vide seção 5) de "progressão continuada" carregam já no nome o peso do simulacro: "regressão continuada", por exemplo, faz um trocadilho que aciona "progressão continuada" (o Outro), para combatê-la e despi-la do conceito que a engendrou. Da mesma forma, "aprovação continuada" também remete à "progressão continuada" (ao Outro) para desqualificá-la, como se não houvesse critérios para promoção dos alunos.

Estamos, assim, diante da faceta discursiva de "progressão continuada”. No entanto, para ser alçada à condição de fórmula discursiva, é preciso, ainda, que seu funcionamento como referente social seja atestado. É ao que me aterei a seguir.

\section{O funcionamento como referente social}

Denominador comum de discursos, a fórmula, para se estabelecer como tal, precisa ser um signo notório, isto é, evocar alguma coisa (não exatamente a mesma coisa) para todos num dado momento. É por isso, inclusive, que o funcionamento como referente social constitui, com a dimensão polêmica, uma relação de interdependência.

De acordo com Krieg-Planque (2010), os critérios que permitem constatar a notoriedade de uma sequência formulaica são numerosos e precisam ser aplicados em conjunto, uma vez que "nenhum deles dá uma resposta definitiva" (p. 92).

Comecemos pela tabela 2 , que exibe com que habitualidade o sintagma em questão apareceu no período compreendido entre 1997 e 2011 no jornal Folha de S. Paulo. ${ }^{18}$

\footnotetext{
${ }^{17}$ Segundo Maingueneau, apesar de estar grafado com letra maiúscula, esse "Outro" não se refere ao homônimo lacaniano, mas simplesmente àquilo que não pertence à formação discursiva da qual se enuncia.

${ }^{18}$ Elegi a Folha para atestar com que frequência o sintagma "progressão continuada" foi empregado ao longo do período descrito por ser ele o maior jornal de circulação no Brasil 2010 - só perdeu para o Super Notícias, de Minas Gerais - conforme divulgado no Instituto Verificador de Circulação (IVC). Para mais detalhes, acesse: <http://rafaeloliveira-rj.blogspot.com/2011/01/jornais-mais-lidos-do-brasil.html>.
} 
TABELA 2

Histórico de ocorrências do sintagma "progressão continuada" no jornal Folha de S. Paulo (de 1997 a 2011)

\begin{tabular}{lc}
\hline Ano & \multicolumn{2}{c}{$\begin{array}{c}\text { Número de edições em que } \\
\text { "progressão continuada” esteve em pauta }\end{array}$} \\
\hline 1997 & 0 \\
1998 & 5 \\
1999 & 1 \\
2000 & 10 \\
2001 & 3 \\
2002 & 27 \\
2003 & 8 \\
2004 & 7 \\
2005 & 4 \\
2006 & 9 \\
2007 & 19 \\
2008 & 12 \\
2009 & 3 \\
2010 & 2 \\
Até $7 / 2011$ & 11 \\
\hline Fonte: & 4 \\
\hline
\end{tabular}

Fonte: Acervo Folha <http://acervo.folha.com.br/>

Graficamente, os valores absolutos ficam assim:

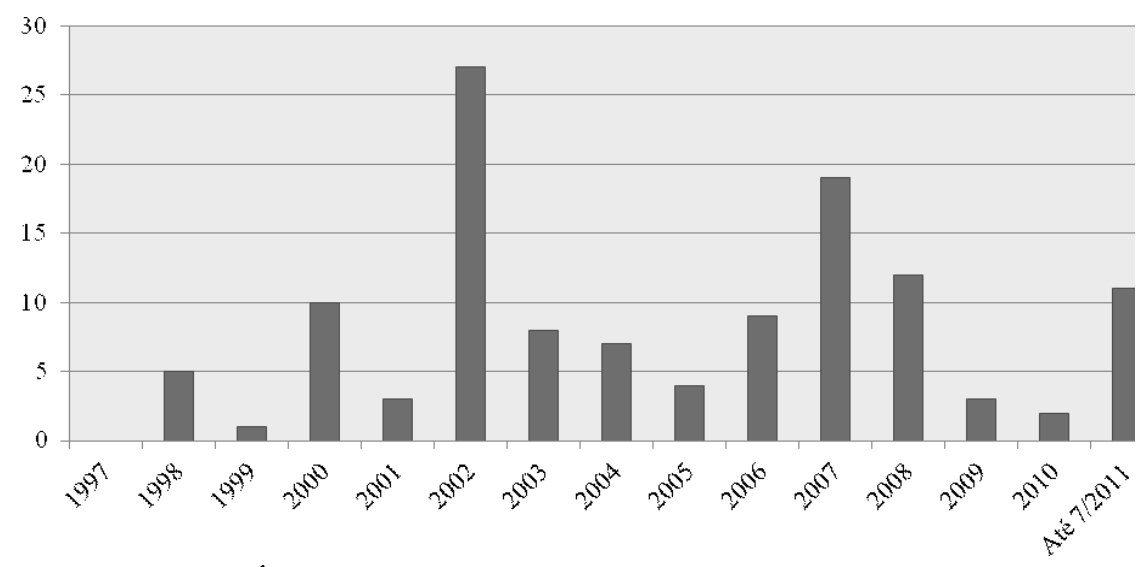

GRÁFICO 1 - Número de edições do jornal Folha de S. Paulo em que "progressão continuada" esteve em pauta (de 1997 a 2011) 
Nota-se que "progressão continuada", desde que o regime ao qual remete começou a vigorar, não parou de circular. O número de ediçóes por ano, embora oscile bastante, revela que o sintagma entrou no espaço público, ou no "corpo social", para usar as palavras de Krieg-Planque (p. 95), considerandose o fato de o jornal Folha de S. Paulo ser o primeiro veículo de maior circulação na capital paulista e interior e o segundo no Brasil.

Chamam a atenção, também, os cadernos nos quais a ocorrência de "progressão continuada" predominou: Primeiro Caderno, Cotidiano, Eleiçōes (caderno sazonal), Ilustrada, Folhinha etc. Partindo do pressuposto segundo o qual é no Primeiro Caderno que estão, entre outras, as colunas Tendências/ Debates, Painel do Leitor e Ombudsman e que estes são espaços em que a palavra é dada a alguém, tal sequência parece ter, de fato, se tornado um ponto de passagem obrigatório.

Além disso, voltando ao corpus de estudo, observa-se a manifestação, no fio do discurso, da estrutura X:P (32 ocorrências). No dizer de Krieg-Planque, esse é um índice não só de que a fórmula remete ao mundo, mas também de que quem a posiciona nessa estrutura pressupõe que o leitor conheça esse mundo. De acordo com Maurice Mouillaud (1982), do lado esquerdo de enunciados desse tipo encontra-se o referente; do lado direito, a informação. Vejamos alguns exemplos: "Progressão continuada: você é a favor ou contra?"19 / "Progressão continuada: como entendê-la" ${ }^{20}$ / "Progressão continuada: em 'recuperação". ${ }^{21}$

As manchetes acima, que intitulam notícias, parecem corroborar o estatuto de referente social de "progressão continuada" no espaço público brasileiro, de 1997 a 2011, pelo princípio da publicização. E a via de divulgação não foi única: além da grande mídia generalista, sites institucionais, blogs (de onde foram retirados artigos de opinião, notícias e reportagens) e fóruns de discussão abriram o caminho para que a sequência ganhasse popularidade no campo midiático.

Sobre esse ponto, aliás, é preciso salientar que, geralmente, a mídia não é

${ }_{19}$ Disponível em: <http://www.fundacaobunge.org.br/interatividade/forum/ topico.php?id=7222\&/progressao _continuada_voce_e_a_favor_ou_contra $>$.

${ }^{20}$ Disponível em: <http://www.aprendeminas.com/2010/12/progressao-continuadacomo-entende-la.html>.

${ }^{21}$ Disponível em: <http://www.educacionista.org.br/jornal/index.php?option= com_content\&task=view\&id=view\&id=8226>. 
a responsável pela gênese de uma fórmula. "Dito de outro modo, se as mídias constituem plataformas de lançamento privilegiadas das fórmulas, não são elas que necessariamente as lançam" (KRIEG-PLANQUE, 2010, p. 118). Esse papel cabe, de acordo com a autora, às formaçóes discursivas, das quais, entretanto, a fórmula deve transbordar para em seguida invadir as práticas linguageiras cotidianas. Só assim poder-se-á dizer que se tornou um referente social.

"Progressão continuada" parece ter ido ao encontro desse percurso: do campo da educação, onde coabitam formações discursivas múltiplas, a favor e contra o regime de ciclos, o sintagma espalhou-se, graças à mídia generalista e aos dispositivos comunicativos eletrônicos referidos anteriormente, pelo espaço público, provocando a manifestação dos cidadãos; logo, leva a crer que se tornou um referente social.

\section{Conclusão}

Sob a lupa da Análise do Discurso, o sintagma "progressão continuada" demonstrou estar em conformidade com as quatro propriedades constitutivas da noção de fórmula (KRIEG-PLANQUE, 2010): seu significante deu indícios de cristalização; as vozes que (ainda hoje) se elevam para sublinhá-lo reforçam sua dimensão polêmica; os posicionamentos que têm aventado põem em evidência sua inscrição discursiva e, por fim, seu uso ao longo de 1997 a 2011 revela seu funcionamento como referente social.

Lembrando que tais aspectos devem tomados em continuum - a prevalência do caráter polêmico sobre os demais parece patente, dada a tônica das declarações anteriormente arroladas (vide item 5) - a conclusão é de que estamos, sim, diante de uma fórmula discursiva.

Muito mais que simples constatação, analisar "progressão continuada" a partir de um aporte discursivo permitiu a compreensão do entorno social no qual ela está mergulhada. Não à toa, a autora francesa assevera que a noção de fórmula é "um recurso fecundo para análise dos discursos políticos, midiáticos e institucionais", uma vez que "o léxico é, em seus empregos políticos e sociais, portador de valores, de argumentos, de engajamentos (KRIEG-PLANQUE, 2010, p. 12 e 30, respectivamente).

De fato, "progressão continuada" funcionou como porta de entrada a um campo discursivo, o da Educação. Mais que isso, ela evidenciou uma mudança de paradigma nele: os parâmetros que antes determinavam a promoção à série subsequente agora não se sustentam mais. É preciso focar no processo como um todo, conforme rezam muitos especialistas da área. 
Ao que tudo indica, estamos, dessa forma, frente a frente com um acontecimento discursivo nos moldes foucaultianos (REVEL, 2005). ${ }^{22}$ Acontecimento este que, ao romper com a história linear da educação brasileira com um advento singular, impôs uma nova postura, principalmente por parte dos professores da rede pública estadual.

Quer dizer, passou-se a esbarrar, assim, em outra questão igualmente pertinente: a atividade de trabalho docente. Afinal, é sobre essa categoria que recaem as cobranças para o êxito do regime de ciclos.

Para dar conta dessa questão, convoco a Ergologia (SCHWARTZ, 2000) - um método de investigação pluridisciplinar, que coloca em dialética os saberes de várias disciplinas para abordar a complexidade do trabalho humano - e a proposta de Pierre Trinquet, para quem "é preciso colocar no centro de nossas preocupaçóes a atividade real do trabalho e não somente a atividade prescrita" (TRINQUET, 2010, p. 107).

Por prescrição, entende-se o que a Ergologia chama de saberes constituídos, isto é, conhecimentos acadêmicos e/ou profissionais exteriores e anteriores à situação de trabalho. A experiência prática (o realizado), por sua vez, corresponde aos saberes investidos. Eles são fruto de renormalizações decorrentes da interação regular do trabalhador com sua atividade de trabalho.

Complementares, os saberes constituídos e investidos apresentam-se como os dois lados de uma mesma moeda. Gerir a distância entre o prescrito e o realizado é, portanto, fundamental para transpor os desafios inerentes a qualquer profissão.

Abordar o trabalho docente segundo a concepção dessa disciplina parece explicar a falta de aderência de vários professores à progressão continuada, uma vez que todo um jeito de fazer (e ser) docente teve de ser posto de lado em prol de uma nova pedagogia até então desconhecida para grande parte dos profissionais. Hélio Schwartsman, articulista da Folha de S. Paulo, sintetizou bem a situação:

Isso [os alunos que não estão assimilando os conteúdos] envolve toda uma estrutura de avaliação fina, aulas de reforço e apoio psicopedagógico com o qual a rede pública não conta. Pior até, a implantação do sistema de ciclos, iniciada em 1997, foi feita de forma desastrosa. A mudança foi ditada de cima para baixo sem explicar a alunos, pais e professores o que se pretendia [...] Na prática, a progressão virou uma aprovação automática

${ }^{22}$ Entendidos aqui como "irrupção de uma singularidade história" (REVEL, 2005, p. 14). 
que, embora não explique as deficiências do ensino, ajuda a perenizá-las (SCHWARTSMAN, 2011).

Justificativas à parte, a Ergologia, ao levar em conta o prescrito e o realizado da atividade do trabalho, talvez possa, por isso mesmo, fornecer as bases teórico-metodológicas para solucionar o impasse travado entre teoria e prática educacionais quando o assunto é o regime de progressão continuada.

\section{Referências}

ALMEIDA, F. J. Progressão continuada não é aprovação automática. Blog de Stella Bortoni, dez. de 2010. Disponível em: <http://www.stellabortoni.com.br/ index.php?option $=$ com_content $\&$ view $=$ article $\&$ id $=2286$ :a-revista-nova-escoladiscute-a-progressao-continuada \&catid=45:blog\&Itemid=1 >. Acesso em: out. 2011. AUTHIER-REVUZ, J. Ces mots qui NE vont pas de soi, Boucles réflexives et noncoüncidences Du dire. Paris, Larousse, 1995. 2 v.

AUTHIER-REVUZ, J. Hétérogenéité montrée et hétérogenéité constitutive: éléments pour une approche de l'autre dans le discours. DRLAV 26, 1982. (Ed. BR.: Heterogeneidade mostrada e heterogeneidade constitutiva: elementos para uma abordagem de outro no discurso. In: Entre a transparência e a opacidade. Porto Alegre; Edipucrs, 2004).

BARROS, L. A. Curso básico de Terminologia. São Paulo: Editora da Universidade de São Paulo, 2004. 285 p.

BERBER SARDINHA, T. Linguistica de Corpus. Barueri-SP: Manole, 2004. 410 p.

BERTAGNA, R. H. Progressão continuada: limites e possibilidades. 2003. 488f. Tese (Doutorado) - Faculdade de Educação da Universidade Estadual de Campinas, 2003. Disponível em: <http://www.bibliotecadigital.unicamp.br/ document $/$ ?code $=$ vtls000297487\&fd=y>. Acesso em: out. 2011 .

BERTAGNA, R. H. Ciclos, progressão continuada e aprovação automática. Educação: Teoria e Prática, v. 18, n. 31, p.73-86, jul./dez. 2008.

CHACON, L. Progressão continuada ou exclusão automática? In: Brasil Econômico apud $\mathrm{O}$ Educacionista, 2010. Disponível em: <http://www.educacionista.org.br/ jornal/index.php? option $=$ com_content $\&$ task $=v i e w \& i d=6883 \&$ Itemid $=43>$. Acesso em: out. 2011.

CHALITA, G. Progressão continuada: espinha dorsal da política educacional. In: Fórum de Debates "Progressão Continuada: Compromisso com a Aprendizagem". São Paulo, 2002. Disponível em: <http://www.crmariocovas.sp.gov.br/pdf/pro/ 05_progressao_continuada_espinha_dorsal.pdf $>$. Acesso em: out. 2011. 
CHRISTIANO, R. Progressão continuada não é vilā. Blog Raul Christiano, 2010. Disponível em: <http://raul.blog.br/660/progressao-continuada-nao-evila/>. Acesso em: out. 2011.

CONTEE. Liminar suspende aprovação automática de alunos em cidade do interior de SP. In Última Instância apud Confederação Nacional dos Trabalhadores em Estabelecimentos de Ensino, fev. de 2009. Disponível em: <http:// www.contee.org.br/noticias/educacao/nedu880.asp>. Acesso em: out. 2011.

CORTELLA, M. S. Aprendizagem em ciclos: repercussão da política pública voltada para a cidadania. In: Fórum de Debates "Progressão Continuada: Compromisso com a Aprendizagem”, São Paulo, 2002. Disponível em: <http:// www.crmariocovas.sp.gov.br/pdf/pro/06_aprendizagem_em_ciclos.pdf $>$. Acesso em: out. 2011.

FELICÍSSIMO, G. Quem poderá nos socorrer? - II. Blog do Gusmão, mar. de 2011. Disponível em: <http://www.blogdogusmao.com.br/v1/2011/03/09/ quem-podera-nos-socorrer-ii/>. Acesso em: out. 2011.

FONTES, C. Insucesso Escolar. Navegando na Educação, 2001. Disponível em: $<$ http://educar.no.sapo.pt/Insucesso.htm>. Acesso em: out. 2011.

FUNDAÇĀO BUNGE. Progressão continuada: você é favor ou contra? Fórum, mar. de 2011. Disponível em: < http://www.fundacaobunge.org.br/interatividade/ forum/topico.php?id=7222\&/progressao_continuada_voce_e_a_favor_ou_ contra>. Acesso em: out. 2011.

GALLO. S. L. Autoria: questão enunciativa ou discursiva? Revista Linguagem em (Dis)curso, v. 1, n.o 2, jan./jun. de 2001. Disponível em: <http://www. portaldeperiodicos.unisul.br/index.php/Linguagem_Discurso/article/view/ 172/186>. Acesso em: out. 2011.

GATTI, B. Representação das entidades. In: Fórum de Debates "Progressão Continuada: Compromisso com a Aprendizagem”. São Paulo, 2002. Disponível em: <http://www.crmariocovas.sp.gov.br/pdf/pro/21_politica_educacional.pdf>. Acesso em: out. 2011.

GUILHERME, C. C. F. O regime de progressão continuada no Estado de São Paulo na voz dos professores de ciclo I: primeiras reflexôes. In: Anais da 23. ${ }^{a}$ Reunião Anual da ANPED, 2000, Caxambu (MG), 2000, p. 128-129.

HAMZE, A. Avaliação escolar. Seção Canal do Educador. Disponível em: <http:// educador.brasilescola.com/trabalho-docente/avaliacao-escolar.htm $>$. Acesso em: out. 2011. 
JESUS, M. P. G. Progressão continuada e avaliação da aprendizagem II. Guarapari (ES), Damarlu Educação, fev. 2011. Disponível em: <http:// damarlueducar.blogspot.com/2011/02/ progressao-continuada-e-avaliacaoda.html>. Acesso em: out. 2011.

KRIEG-PLANQUE, A. A noção de "fórmula" em Análise do Discurso: quadro teórico-metodológico. Trad. Luciana Salazar Salgado e Sírio Possenti. São Paulo: Parábola Editorial, 2010.

KRIEG-PLANQUE, A. "Fórmulas" e "lugares discursivos": propostas para a análise do discurso político. In: MOTTA, A. R.; SALGADO, L (Org.). Fórmulas discursivas. São Paulo: Contexto, 2011. p. 11-40. Entrevista concedida a Philippe Schepens.

KOCOUREK, R. La langue française de la technique et de la science. 2è éd. Wiesbaden: Oscar Brandstetter Verlag, 1991.

LEME, R. A. T. A Progressão continuada e o sistema de ciclos: mais uma reforma escolar. In: Fórum de debates "Progressão Continuada: Compromisso com a Aprendizagem”, São Paulo, 2002. Disponível em: <http://www.crmariocovas.sp. gov.br/pdf/pro/TEXTO4.pdf>. Acesso em: out. 2011.

MAINGUENEAU, D. Gênese dos discursos. Trad. Sírio Possenti. São Paulo: Parábola, 2008. 184 p.

MELO, P. A farsa da progressão continuada - parte I. Recanto das Letras, 2011. Disponível em: <http://www.recantodasletras.com.br/artigos/2751022>. Acesso em outubro de 2011.

MLRODRIG. Conhecimento, progressão continuada e como matar a criatividade no ambiente de trabalho. Blog Tecnologias de Rede, Mobilidade e Inovação, out. de 2010. Disponível em: <http://under-linux.org/blogs/ mlrodrig/conhecimento-progressao-continuada-e-como-matar-criatividade-noambiente-de-2245/>. Acesso em: out. 2011.

MMOUILLAUD, M. Grammaire et idéologie du titre de journal, in Mots. Ordinateurs. Textes. Sociétés (Paris: Presses de la Fondation Nationale dês Sciences Politiques), n. 4, março, p. 69-90, 1982.

MOTTA, A. R.; SALGADO, L. Fórmulas Discursivas. São Paulo: Editora Contexto, 2011. 176 p.

NORONHA, M. I. A. Exclusão Postergada dos Alunos. In: Folha de S. Paulo, Tendências/Debates, jan. de 2011. Disponível em: http://apeoesp.wordpress. $\operatorname{com} / 2011 / 01 / 29 /$ folha-de-s-paulo-debate-a-progressaocontinuada/>. Acesso em: out. 2011. 
OBSERVATÓRIO DA EDUCAÇÃO. Progressão continuada não pode ser responsabilizada pela falta de qualidade na educação. Fórum, ago. de 2006. Disponível em: <http://www.observatoriodaeducacao.org.br/index.php?view= article $\& i d=288 \% 3$ Aprogressao-continuada-nao-pode-ser-responsabilizadapela-falta-de-qualidade-na-educacao $\&$ option $=c o m_{-}$content $\&$ Itemid $=98>$. Acesso em: out. 2011.

O EDUCACIONISTA. Progressão continuada: em 'recuperação'. In: Jornal da cidade de Bauru, mar. de 2011. Disponível em: <http://www.educacionista. org.br/jornal/index.php? option=com_content\&task=view $\&$ id $=8226>$. Acesso em: out. 2011.

OLIVEIRA, Z. M. R. Avaliação da aprendizagem e progressão continuada: bases para a construção de uma nova escola. Revista de Estudos e Avaliação Educacional, São Paulo, Fundação Carlos Chagas, jul./dez. de 1998, p. 7-12. Disponível em: <http://www.crmariocovas.sp.gov.br/int_a.php?t=003>. Acesso em: out. 2011. ORLANDI, E, P. As formas do silêncio: no movimento dos sentidos. 2. ${ }^{\mathrm{a}} \mathrm{ed}$. Campinas: Editora da Unicamp, 2007. 181 p.

PÊCHEUX, M. Discurso: estrutura ou acontecimento. Trad. Eni Puccinelli Orlandi. 5. ed. Campinas: Pontes Editores, 2008. 68 p.

PEREIRA, D, B. O regime de progressão continuada e as implicaçôes na organização escolar em escolas da rede estadual de ensino do município de Santa Maria/RS. 2006. 136f. Dissertação (Mestrado) - Programa de Pós-Graduação em Educação, Universidade Federal de Santa Maria (UFSM), Rio Grande do Sul, 2006. Disponível em: <http://cascavel.cpd.ufsm.br/tede/tde_arquivos/18/TDE2006-12-14T093603Z-296/Publico/ daiana\%20pereira.pdf>. Acesso em: out. 2011.

PEREIRA, D. B.; TERRAZZAN, E. A. Reorganização do sistema escolar: estudo sobre as propostas de progressão contínua e de progressão parcial nas escolas estaduais de Santa Maria - RS. IV Encontro Iberoamericano de Coletivos Escolares e Redes de Professores que Fazem Investigação na sua Escola. Lajeado (RS), UNIVATES, jul. de 2005. Disponível em: <http://ensino.univates.br/ -4iberoamericano/trabalhos/trabalho151.pdf>. Acesso em: out. 2011.

PETRENAS, R. C.; LIMA, R. C. P. Representaçôes sociais de professores sobre ciclos de aprendizagem e a progressão continuada. São Paulo: Múltiplas Leituras, Universidade Metodista, n. ${ }^{\circ}$ 1, 2006. Disponível em: <http://www.metodista. $\mathrm{br} / \mathrm{ppc} / \mathrm{multiplas-leituras/multiplas-leituras-01/representacoes-sociais-de-}$ professores-sobre-ciclos-de-aprendizagem-e-a-progressao-continuada $>$. Acesso em: out. 2011. 
PICOCHE, J. Précis de lexicologie française. Paris: Nathan Université, [1977], 1992.

PORTAL LUÍS NASSIF. A progressão continuada. Fórum de discussão, jul. de 2008. Disponível em: <http://blogln.ning.com/forum/topics/2189391: Topic:9415>. Acesso em: out. 2011.

REVEL, J. Michel Foucault: Conceitos essenciais. Trad. Maria do Rosário Gregolin, Nilton Milanez, Carlos Piovesani. São Carlos (SP): Claraluz, 2005, 87 p.

R7. Mercadante diz que progressão continuada é "regressão" e Alckmin defende sistema. Eleições 2010/Notícias, set. de 2010. Disponível em <http:// noticias.r7.com/eleicoes-2010/noticias/mercadante-diz-que-progressaocontinuada-e-regressao-e-alckmin-defende-sistema-20100915.html>. Acesso em: out. 2011.

SCHWARTZ, I. Trabalho e uso de si. Trad. M. L. R. Leão, tradução das notas e revisão técnica de Maria Inês Rosa. Pro-Posiçôes, v.1, n. 5, v. 32, p. 34-50, jul. 2000 .

SCHWARTSMAN, H. Implantação do sistema de ciclos pulou etapas. Luis Nassif Online, jan. de 2011. Disponível em: <http://www.advivo.com.br/blog/ luisnassif/as-mudancas-na-progressao-continuada>. Acesso em: out. 2011.

SCOTT, M. WordSmith Tools 3.0. (1999). Lexical Analysis Software Ltd.; Oxford University Press. Disponível em: <http://www.lexically.net/downloads/ version3/download.htm>. Acesso em: out. 2011.

SINCLAIR, J. M. Corpus, Concordance, Collocation. London: Oxford University Press, 1991. 179 p.

TRINQUET, P. Trabalho e educação: o método ergológico. Revista HISTEDBR On-line, n. especial, 2010. p. 93-113. Disponível em: <http://www.histedbr. fae.unicamp.br/revista/edicoes/38e/art07_38e.pdf>. Acesso em: out. 2011.

VIER, S. Progressão continuada alastra analfabetismo funcional em SP, afirmam professores. Rede Brasil Atual, ago. de 2010. Disponível em: <http://www. redebrasilatual.com.br/temas/educacao/2010/08/progressao-continuada-alastraanalfabetismo-funcional-em-sp-afirmam-professores $>$. Acesso em: out. 2011.

VIEIRA, G. Progressão continuada só funciona com políticas de apoio. Globo.com, jun. de 2010. Disponível em: <http://colunas.imirante.com/platb/ gastaovieira/2010/06/11/ progressao-continuada-so-funciona-com-politicas-deapoio/>. Acesso em: out. 2011. 